\title{
A comparative study on the usefulness of the Glidescope or Macintosh laryngoscope when intubating normal airways
}

\author{
Guen Seok Choi, Eun-Ha Lee, Chae Seong Lim, and Seok-Hwa Yoon \\ Department of Anesthesiology and Pain Medicine, Chungnam National University School of Medicine, Daejeon, Korea
}

Background: The Glidescope Videolaryngoscope (GVL) is a newly developed video laryngoscope. It offers a significantly improved laryngeal view and facilitates endotracheal intubation in difficult airways, but it is controversial in that it offers an improved laryngeal view in normal airways as well. And the price of GVL is expensive. We hypothesized that intubation carried out by fully experienced anesthesiologists using the GVL with appropriate pre-anesthetic preparations offers an improved laryngeal view and shortened intubation time in normal airways. Therefore, the aim of this study was to compare the GVL with the Macintosh laryngoscope in normal airways and to determine whether GVL can substitute the Macintosh laryngoscope.

Methods: This study included 60 patients with an ASA physical status of class 1 or 2 requiring tracheal intubation for elective surgery. All patients were randomly allocated into two groups, GVL (group G) or Macintosh (group M). ADS (airway difficulty score) was recorded before induction of anesthesia. The anesthesiologist scored vocal cord visualization using the percentage of glottic opening (POGO) visible and the subjective ease of intubation on a visual analogue scale (VAS). The time required to intubate was recorded by an assistant.

Results: There was a significant increase in POGO when using the GVL $(\mathrm{P}<0.05)$. However, there was no difference in the time required for a successful tracheal intubation using the GVL compared with the Macintosh laryngoscope. The VAS score on the ease of intubation was significantly lower for the GVL than for the Macintosh laryngoscope $(\mathrm{P}<0.05)$.

Conclusions: GVL could be a first-line tool in normal airways. (Korean J Anesthesiol 2011; 60: 339-343)

Key Words: Glidescope, Intubation, Macintosh laryngoscope.

Received: July 19, 2010. Revised: November 2, 2010. Accepted: November 14, 2010.

Corresponding author: Seok-Hwa Yoon, M.D., Ph.D., Department of Anesthesiology and Pain Medicine, Chungnam National University School of Medicine, 33, Munhwa-ro, Jung-gu, Daejeon 301-721, Korea. Tel: 82-42-280-7840, Fax: 82-42-280-7968, E-mail: seohwy@cnu.ac.kr (c) This is an open-access article distributed under the terms of the Creative Commons Attribution Non-Commercial License (http:// creativecommons.org/licenses/by-nc/3.0/), which permits unrestricted non-commercial use, distribution, and reproduction in any medium, provided the original work is properly cited. 


\section{Introduction}

Tracheal intubation is an essential step in securing the airway during general anesthesia. Therefore, performing rapid intubation impeccably is one of the most intense procedures required by an anesthesiologist. In general, a Macintosh blade is used during induction of general anesthesia. However, there are times when this process is met with difficulty. When airway maintenance and ventilation is difficult, brain damage due to hypoxia and hypercarbia may occur [1]. Other complications such as dental damage due to multiple attempts of intubation, laryngospasm, bronchospasm, etc. may also arise. Therefore, many tools are being developed for easier intubation, and testing their usefulness in the clinical field is increasing. Amongst these tools include, the Glidescope videolaryngoscope (GVL, Glidescope ${ }^{\circledR}$, Saturn Biomedical Systems Inc.) which is widely used during difficult intubations [2-4]. It is also widely acknowledged to be more useful than the Macintosh laryngoscope [5-10]. However, while there are studies claiming that intubation time with the GVL is increased in the general patient population $[5,8,10,11]$, other studies state that the intubation time is similar $[9,12]$, and some state the GVL decreases intubation time [13,14]. GVL is an expensive tool and it is difficult to purchase various shapes and sizes of blades [15]. Since sterilization is also rather difficult compared to the Macintosh blade, its use for all patients is limited.

In this study, patients presumed not to meet difficult intubation criteria based on a pre-anesthetic evaluation were allocated into two groups, the GVL group and the Macintosh group: they were evaluated on ease of intubation using individual

Table 1. Demographic Data

\begin{tabular}{lcc}
\hline & $\begin{array}{c}\text { Group M } \\
(\mathrm{n}=30)\end{array}$ & $\begin{array}{c}\text { Group G } \\
(\mathrm{n}=30)\end{array}$ \\
\hline Age (yr) & $43.0 \pm 14.9$ & $39.5 \pm 13.4$ \\
Sex (M/F) & $15 / 15$ & $16 / 14$ \\
Height (cm) & $162.8 \pm 10.5$ & $166.0 \pm 8.2$ \\
Weight (kg) & $61.2 \pm 11.7$ & $64.5 \pm 9.2$ \\
ADS & $6.6 \pm 0.6$ & $6.7 \pm 0.9$ \\
\hline
\end{tabular}

Group M: macintosh laryngoscope, Group G: glidescope videolaryngoscope, ADS: airway difficulty score.

Table 2. Airway Difficulty Score (ADS)

\begin{tabular}{lccc}
\hline & 1 & 2 & 3 \\
\hline Thyromental distance & $>6 \mathrm{~cm}$ & $5-6 \mathrm{~cm}$ & $<5 \mathrm{~cm}$ \\
Mallampati class & Class I & Class II & Class III \\
Mouth opening & $4 \mathrm{~cm}$ & $2-3 \mathrm{~cm}$ & $1 \mathrm{~cm}$ \\
Neck mobility & Normal & Reduced & Fixed flexion \\
Upper incisors & Absent & Normal & Prominent \\
\hline
\end{tabular}

If score $\geq 8$ : ventilation and/or intubation likely to be difficult.
VAS scores and the time required for intubation. The aim of this study was to determine whether all tracheal intubation, including difficult airways, could use the GVL as the first choice in intubation.

\section{Materials and Methods}

The study was approved by the Ethics Committee of our institute and informed consent was obtained from all patients. This study enrolled 60 patients classified as ASA class 1 and 2 scheduled to undergo general anesthesia between the ages of 15 and 60 years (Table 1 ).

All patients were randomly allocated into group $M$ (Macintosh) or group G (GVL). All evaluations and tracheal intubations with both the Macintosh laryngoscope and GVL were performed by one anesthesiologist. ADS (Airway difficulty score) [1] was assessed prior to intubation in order to exclude those predicted to make the procedure difficult (Table 2). Patients with a thyroid-to-chin length of $5 \mathrm{~cm}$ or shorter, a Mallampati class 3 or higher, mouth opening less than $3 \mathrm{~cm}$, restriction in neck extension or protruding front teeth were predicted to be difficult in intubation and were thus excluded from the study. Also, patients with an ADS score above 8 including the evaluation criteria mentioned above were also predicted to be difficult in intubation and were thus excluded as well.

In order to evaluate the ease of intubation, first, the POGO (Percentage of glottic opening) [16] was estimated (Fig. 1). POGO score was evaluated and recorded on a subjective view on how well the vocal cords were seen. Secondly, difficulty on intubation by the anesthesiologist was scored by a VAS ( 0 being most easy, 10 being most difficult). Thirdly, an assistant recorded the intubation time, which was from when the anesthesiologist grabbed the handle to when the tube passed
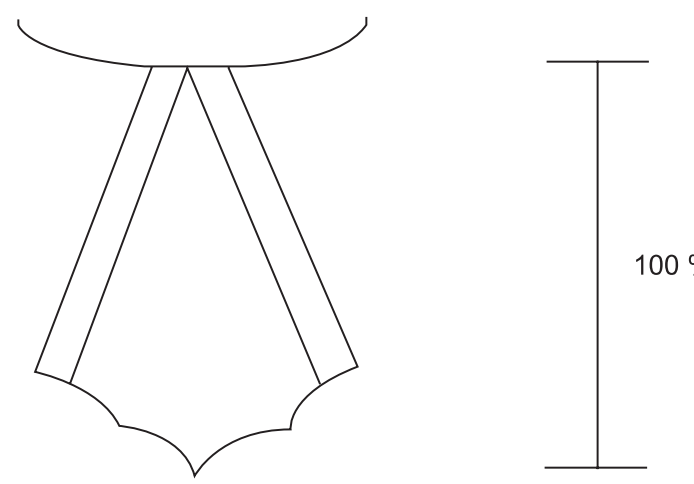

Fig. 1. The percentage of glottis opening (POGO) score. It represents the portion of the glottis visualized. The score ranges from $0 \%$ when none of the glottis is seen to $100 \%$ when the entire glottis including the anterior commissure is seen. 
the vocal cords. The assistant pressed the cricoid cartilage to make intubation easier.

All patients were expected to fast 8 hours before surgery, and were premedicated with $2 \mathrm{mg}$ of midazolam and $0.2 \mathrm{mg}$ of glycopyrrolate intramuscularly 30 minutes before surgery. Anesthetic induction was preformed with $40 \mathrm{mg}$ of lidocaine and $1.5 \mathrm{mg} / \mathrm{kg}$ of propofol, and when consciousness was lost, 0.6 $\mathrm{mg} / \mathrm{kg}$ of rocuronium was injected. After, making sure that all four TOF responses of the Adductor Pollicis disappeared, which ensures sufficient musclular blockade, intubation was then performed. A number 3 blade was used in all patients.

SPSS version 13.0 (SSPS Inc. Chicago, IL, USA) was used for statistical analysis and comparison of each group was analyzed using a student $\mathrm{T}$ test. All measurements are expressed as mean \pm standard deviation, with $\mathrm{P}$ value of $<0.05$ being statistically significant.

\section{Results}

There were no statistical differences in age, sex, height, weight and ADS between the two groups (Table 1 and 3). Results evaluating intubating ease are as follows:. first, POGO scores in group $M$ and group $G$ were $67.6 \pm 24.7 \%$ and $89.6 \pm 20.0 \%$, respectively with a significantly higher POGO score in group G. Second, subjective difficulty in intubation by the VAS scores were $2.8 \pm 1.5$ and $1.9 \pm 1.3$ in group $M$ and group $G$, respectively indicating significantly lower VAS scores for group G. Third, intubation times in groups $\mathrm{M}$ and $\mathrm{G}$ were $18.6 \pm 5.1 \mathrm{~s}$ and 18.2 \pm 5.0 s, respectively demonstrating that these times were not significantly different.

\section{Discussion}

After being first introduced in 1943, the Macintosh laryngoscope has been the most widely used tool for intubations, and most cases are successful without major problems. However, there are instances when intubation becomes difficult, and according to Benumof's study [17], issues occur $0.05-0.35 \%$

Table 3. Clinical Data

\begin{tabular}{lcc}
\hline & $\begin{array}{c}\text { Group M } \\
(\mathrm{n}=30)\end{array}$ & $\begin{array}{c}\text { Group G } \\
(\mathrm{n}=30)\end{array}$ \\
\hline POGO score (\%) & $67.6 \pm 24.7$ & $89.6 \pm 20.0^{*}$ \\
Intubation time (sec) & $18.6 \pm 5.1$ & $18.2 \pm 5.0$ \\
Ease of intubation (VAS) & $2.8 \pm 1.5$ & $1.9 \pm 1.3^{*}$ \\
\hline
\end{tabular}

Values are mean \pm SD. Group M: macintosh laryngoscope, Group G: glidescope videolaryngoscope. POGO: percentage of glottic opening. There were significant differences in POGO score and ease of intubation between the two groups $(\mathrm{P}<0.05)$. $* \mathrm{P}$ value $<0.05$ by two sample t-test. of the time. Failure of intubation may result from dental damage, laryngospasm, bronchospasm, bleeding, hypoxia, and hypercarbia and intubation may even cause fatal complications such as brain damage. Therefore, increasing the success rate by improving the ease of tracheal intubation is an important task for anesthesiologists. Many tools are constantly being developed to improve successful intubation, and in the past few years, the invention of the GVL has been a great improvement.

There have been many video laryngoscopes invented, including the commonly used GVL, Pentax-AWS (Pentax Corporation, Japan) and Airtraq optical laryngoscope (Airtraq, Prodol Meditec, Spain), among others [18]. The GVL carries a magnified screen with an anti-fog device to allow easy intubation. On the other hand, because the video camera of the GVL is located on the curved blade, the epiglottis is actually located anterior to where the practitioner thinks it is located. Plus, the actual view and screen are separated, making it may be difficult for a novice to perform the procedure. If not interfered by oral secretions, Pentax-AWS is widely known to easily perform intubations thru a highly definitive screen. However, intubation must be carried out by the Miller method, which is performed by entering the blade along the laryngo-pharyngeal wall causing secretions to enter into the blade and interfering with the visual field. The Airtraq is a relatively inexpensive, light tool which lacks a quality screen but is sufficient for intubation. It carries an anti-humidity device and allows magnification of the view, providing manipulation at an adequate distance. But, the practitioner must be fully familiar with operating the device [18].

Among these tools, the GVL has been used in many studies because of its advantages compared to a general laryngoscope. First, because the view of the airway is magnified with the GVL, the operator can fully observe the airway. Second, because the camera is located in the front part of the blade which is bent at a 60 degree angle, parts which were impossible to see with a general laryngoscope can now be observed. Third, because others can observe the procedure, it may be a helpful, educational tool [2-4]. However, the GVL is a very expensive and it is difficult to purchase various shapes and sizes of blades [15]. Further, sterilization of the blade is difficult compared to the Macintosh blade and collectively, these issues have restricted the use of the GVL in a typical patient. However, if it is proved that the GVL is superior to the Macintosh laryngoscope during intubation, the downfalls may be overlooked.

An agreement on the efficiency of the GVL during difficult intubation is being established. However, some reports state that there is no significant difference in the efficiency of using the GVL compared to the Macintosh laryngoscope $[9,19]$ and some studies conclude that it is even more time consuming $[8,10,11]$. We presume that the reason for these results were 
because of the following. First, a doctor familiar with the Macintosh laryngoscope and inexperienced with the use of the GVL may have attempted intubation. Second, preparations including properly locating the GVL monitor to a position where the anesthesiologist can see adequately as well as insertion of the stylet before intubation may not have been done. Third, contrary to actually visualizing the vocal cords when intubating using the Macintosh laryngoscope, when using GVL one must see the monitor while inserting the tube. Fourth, the camera on the GVL blade, which is bent to 60 degrees, displays a rather different view than when using the Macintosh laryngoscope. Also, the Macintosh blade is structurally different and the view of the epiglottis differs due to the location of the vallecula, leading to potential issues. Therefore, this study was carried out by a fully experienced anesthesiologist familiar with the GVL, and intubated the patient when preparations were fully taken. The POGO score was used to evaluate the efficiency of the intubation in this study because, between doctors, it is more reliable than the Cormack-Lehane classification when examining the laryngeal view [15]. The ADS criteria, which was created by Janssen and Hartstein [1], was used in this study to predict difficult airway intubations,. Patients with a score of 8 or above were considered to be difficult in upper airway ventilation and had an oro-laryngo-pharyngeal axis that was difficult to straighten. In this study, there were no significant differences in ADS between the two groups, meaning the degree of airway difficulty was similar. Also, 3 patients from group $\mathrm{M}$ and 4 from group $\mathrm{G}$ who either had either a total of 8 or more points or 3 points in the 5 criteria were excluded from the study. The average POGO scores for groups $\mathrm{M}$ and $\mathrm{G}$ were 40 and 67 , respectively. Although not statistically significant due to the relatively small number of patients participating in the study, we can assume that the GVL is more efficient in cases of difficult airways.

Intubation of group $\mathrm{G}$ was likely more comfortable with the GVL since there was no need to align the oro-laryngo-pharyngeal axis to view the vocal cords, allowing visualization of structures unable to be seen with the Macintosh laryngoscope. Also, because an assistant can also see the intubation process through a magnified screen, he or she may adequately aid in Sellick's maneuver. Ayoub et al. [14] divided 42 unexperienced students into two groups to carry out intubation with either the Macintosh laryngoscope or the GVL. Results showed that the group using the GVL had a higher success rate and took less time for the intubation. Therefore, we can see that even novices can easily intubate using the GVL.

This study used ADS solely as an index in assessing difficult airways, but a deeper analysis on the advantages of the GVL compared to the Macintosh laryngoscope may have more interesting results. For instance, the GVL is useful if neck extension is limited, but its usefulness has not been evaluated according to the Mallampati classification, thyroid-chin distance, and the degree of mouth opening. Therefore, further studies may obtain more in-depth results.

In conclusion, in patients that were presumed to have normal airways, the GVL allows a wider laryngeal view than the Macintosh laryngoscope so the practitioner may more easily and comfortably carry out intubation and consider it as the instrument of choice.

\section{References}

1. Janssens M, Hartstein G. Management of difficult intubation. Eur J Anaesthesiol 2001; 18: 3-12.

2. Sakles JC, Rodgers R, Keim SM. Optical and video laryngoscopes for emergency airway management. Intern Emerg Med 2008; 3: 139-43.

3. Benjamin FJ, Boon D, French RA. An evaluation of the Glidescope, a new video laryngoscope for difficult airways: a manikin study. Eur J Anaesthesiol 2006; 23: 517-21.

4. Cooper RM, Pacey JA, Bishop MJ, McCluskey SA. Early clinical experience with a new videolaryngoscope (Glidescope) in 728 patients. Can J Anaesth 2005; 52: 191-8.

5. Serocki G, Bein B, Scholz J, Dörges V. Management of the predicted difficult airway: a comparison of conventional blade laryngoscopy with video-assisted blade laryngoscopy and the GlideScope. Eur J Anaesthesiol 2010; 27: 24-30.

6. Lim Y, Yeo SW. A comparison of the GlideScope with the Macintosh laryngoscope for tracheal intubation in patients with simulated difficult airway. Anaesth Intensive Care 2005; 33: 243-7.

7. Bathory I, Frascarolo P, Kern C, Schoettker P. Evaluation of the GlideScope for tracheal intubation in patients with cervical spine immobilisation by a semi-rigid collar. Anaesthesia 2009; 64: 133741.

8. Narang AT, Oldeg PF, Medzon R, Mahmood AR, Spector JA, Robinett DA. Comparison of intubation success of video laryngoscopy versus direct laryngoscopy in the difficult airway using high-fidelity simulation. Simul Healthc 2009; 4: 160-5.

9. Kim HJ, Chung SP, Park IC, Cho J, Lee HS, Park YS. Comparison of the GlideScope video laryngoscope and Macintosh laryngoscope in simulated tracheal intubation scenarios. Emerg Med J 2008; 25 : 279-82.

10. Lim TJ, Lim Y, Liu EH. Evaluation of ease of intubation with the GlideScope or Macintosh laryngoscope by anaesthetists in simulated easy and difficult laryngoscopy. Anaesthesia 2005; 60: 180-3.

11. Powell L, Andrzejowski J, Taylor R, Turnbull D. Comparison of the performance of four laryngoscopes in a high-fidelity simulator using normal and difficult airway. Br J Anaesth 2009; 103: 755-60.

12. Hirabayashi Y, Otsuka Y, Seo N. GlideScope videolaryngoscope reduces the incidence of erroneous esophageal intubation by novice laryngoscopists. J Anesth 2010; 24: 303-5.

13. Wayne MA, McDonnell M. Comparison of traditional versus video laryngoscopy in out-of-hospital tracheal intubation. Prehosp Emerg Care 2010; 14: 278-82.

14. Ayoub CM, Kanazi GE, Al Alami A, Rameh C, El-Khatib MF. Tracheal intubation following training with the GlideScope com- 
pared to direct laryngoscopy. Anaesthesia 2010; 65: 674-8.

15. Song JG, Kwon MA. Use of the Airtraq(R) optical laryngoscope as a rescue airway device following failed awake flexible fiberoptic nasotracheal intubation of a patient with severe microsomia: A case report. Korean J Anesthesiol 2008; 55: 353-7.

16. Ochroch EA, Hollander JE, Kush S, Shofer FS, Levitan RM. Assessment of laryngeal view: percentage of glottic opening score vs Cormack and Lehane grading. Can J Anaesth 1999; 46: 987-90.
17. Benumof JL. Management of the difficult adult airway. With special emphasis on awake tracheal intubation. Anesthesiology 1991; 75: 1087-110.

18. Sakles JC, Rodgers R, Keim SM. Optical and video laryngoscopes for emergency airway management. Intern Emerg Med 2008; 3: 139-43.

19. Tak YJ, Kim SJ, Kim ST. A comparison-study of the effects of conventional and video laryngoscopic intubation on heart rate and blood pressure. Korean J Anesthesiol 2008; 54: 513-8. 